\title{
Dietary Patterns of Children during the First Year of Life: A Cohort Study
}

\section{-Dietary Patterns of Children}

\author{
Angelina Do Carmo Lessa ${ }^{*}$, Lorena Barbosa Fonseca2 ${ }^{2}$, Luciana Neri Nobre1, \\ Ana Marlúcia De Oliveira Assis ${ }^{3}$ \\ ${ }^{1}$ Department of Nutrition, Federal University of Jequitinhonha and Mucuri Valleys, Diamantina, Brazil \\ ${ }^{2}$ Faculty of Nutrition, Federal University of Mato Grosso, Cuiabá, Brazil \\ ${ }^{3}$ School of Nutrition, Post-Graduation Program in Food and Nutrition, Department of Nutritional Sciences, \\ Federal university of Bahia (UFBA), Salvador, Brazil \\ Email: *angelinalessa@hotmail.com
}

How to cite this paper: Lessa, A.C., Fonseca, L.B., Nobre, L.N. and Assis, A.M.O. (2017) Dietary Patterns of Children during the First Year of Life: A Cohort Study. Food and Nutrition Sciences, 8, 1001-1011. https://doi.org/10.4236/fns.2017.811072

Received: October 5, 2017

Accepted: November 19, 2017

Published: November 22, 2017

Copyright ( 2017 by authors and Scientific Research Publishing Inc. This work is licensed under the Creative Commons Attribution International License (CC BY 4.0).

http://creativecommons.org/licenses/by/4.0/

(c) (i) Open Access

\begin{abstract}
Objective: To identify the dietary patterns of children during the first year of life. Methods: This is a longitudinal study of children born between September 2004 and April 2005 residing in Diamantina, MG, Brazil. Data were collected from children who were six, nine and twelve months of age. Data were collected at their homes using a questionnaire that included a socioeconomic and demographic profile of the family. Information on diet was obtained using 24 hour food recall. Principal Component Analysis was used to identify the dietary patterns. Results: Three dietary patterns were identified and denominated "Porridge", "Pap" and "Family Food". The most common dietary pattern was composed of milk, sugar and fortified flour and was negatively correlated with breastfeeding. The second dietary pattern was composed of tubers, vegetables and fruits. The third dietary pattern consisted of cereal, meat, beans and tea; this pattern was repeated at different ages, with some variation at the sixth month when artificial drinks were included and meat and tea were excluded. Conclusion: There was some variation in the dietary patterns of children; however, porridge was used predominantly in all studied ages. Information on dietary patterns may be useful for evaluating and redirecting food and nutrition policies.
\end{abstract}

\section{Keywords}

Complementary Feeding, Factor Analyses, Dietary Patterns

\section{Introduction}

Adequate nutrition during childhood is crucial to ensure the full development of 
human potential because privations during this part of the life cycle limit the ability of children to achieve adequate growth and development. This period corresponds to the highest incidence of stunting, micronutrient deficiency, and infectious disease [1].

To promote health and adequate nutrition, the World Health Organization (WHO) recommends breastfeeding exclusively during the first six months of life and the gradual introduction of complementary feeding at six months [2].

However, Brazilian studies indicate that the timing of complementary feeding and the quantitative and qualitative adequacy of the foods are flawed [3]. The gradual abandonment of breastfeeding and the early replacement of breast milk with cow's milk are often observed. This substitution contributes to high morbidity and mortality in the first year of life in developing countries [4]. Data from Multicenter Study of Food Consumption, conducted in some Brazilian cities, shows that the most frequently consumed foods have been cow's milk, flour, sugar, biscuits, rice, beans, potatoes and noodles [3]. Some variation in the diet among Brazilian children was noted this way.

The early replacement of breast milk with cow's milk through porridge containing added thickeners and sugars has been reported in several studies throughout Brazil; this prepared food plays an important role in the nutrition of children in the year of life [5] [6]. Conversely, the introduction of the meat food group is often delayed [5] [7]. This pattern was described by Assis et al. [8] in a study of children younger than five years in Salvador-BA-Brazil. According to the authors, in children between six and twelve months of age, the consumption of meat was very low, and even when the meat was part of the diet, the amount was insufficient to meet micronutrients requirements [11].

Most studies assessing food intake, analyze the adequacy of macronutrient, micronutrient and calorie consumption based on estimated requirements for the population group by age and sex. However, meals are generally composed of a variety of foods. Particular combinations of foods can result in different metabolic effects by producing chemical interactions that create antagonistic, competing effects or that change the bioavailability of nutrients or chemicals [9].

The World Health Organization suggests that evaluations should be based on dietary patterns. As food consumption often occurs in a combined way, it is difficult to determine either the protective or deleterious health effects of particular foods. Therefore, the entire diet should be considered in addition to particular foods and nutrients [10]. Nonetheless, no dynamic cohort study in which a factor analysis was used for the construction of dietary patterns during the introduction of complementary feeding was identified. Based on these considerations, this study aimed to characterize the dietary patterns of children at six, nine and twelve months of age.

\section{Materials and Methods}

\subsection{Design and Study Population}

This longitudinal investigation of children born between September 2004 and 
April 2005 was conducted in Diamantina, Minas Gerais, Brazil. This birth group is part of a study whose objectives included identifying the feeding patterns of children during their first year of life. Diamantina is located in the High Jequitinhonha Valley. Its population is 46.372 inhabitants, and its human development index (HDI) is 0.748 .

For a Principal Components Analysis (PCA), the minimum sample size (number of children in each age) must be at least five times the number of variables (number of food groups). Thus, the number of observations for each variable was obtained by dividing the number of observations that were selected for the factor analysis. Therefore, it was the values 19, 17 and 16 at six, nine and twelve months were obtained, respectively, which were higher than the recommended values of at least five times the number of variables [11].

\subsection{Data Collection}

The cohort was recruited using information from Certificate of Live Birth (CLB), which were collected every two weeks from the Municipal Health Department where all CLB were stored. Every child born who lived in the seat of the municipality was recruited to the study to ensure the inclusion of the total number of births during the study period.

Data collection was performed in the children's houses using a form in which the socioeconomic and demographic characteristics of the family were recorded. The variables were stratified, as presented in Table 1 . Information about children's diets was collected using a 24-hour diet recall. The food intake data was collected during home visits at six, nine and twelve months of age. Feeding information was provided by the caregiver, frequently the mother. The inclusion criterion was to reside at the seat of the municipality. Children suffering from congenital deficiencies and the twins were excluded.

\subsection{Dietary Patterns}

The food items obtained from a 24-hour dietary recall were grouped and coded according to individual consumption: the child does not consume the food (1) or the child consumes the food (0). First, we identified 16 feeding groups from 94 food items identified based on common characteristics of the nutritional content of the food. The minimum frequency for input item into the factor analysis in the factor analysis was set at 5\%. Based on this criterion, 31 of the 94 food items (Table 1) reached the minimum frequency at some point in the study, and 13 groups of selected foods were included in the factor analysis.

\subsection{Statistical Analysis}

To identify dietary patterns, the factor analysis methodology of PCA was applied to the data obtained from the 24-hour diet recall. Before the calculation of the factor analysis, the Kaiser-Mayer-Olkin (KMO) coefficient was estimated, and Bartlett's test of sphericity was applied to assess the quality of the correlations 
Table 1. Grouping of foods used in the analysis of patterns according to nutrient content and botanical composition. Diamantina (MG), Brazil, 2004-2006.

\begin{tabular}{|c|c|}
\hline FoodGroup & Food Item \\
\hline Milk & Cow's milk $^{\star}$, formula ${ }^{\star}$, Petit Suisse ${ }^{\star}$, yogurt ${ }^{\star}$, fermented milk \\
\hline Breastmilk & Breast milk* \\
\hline Sugar & Sugar ${ }^{\star}$, chocolate, honey \\
\hline Fortified flour & Mucilon*, flour and milk, cremogema, neston, sustagem. \\
\hline Flour & Creamed corn*, corn flour, oat, wheat flour \\
\hline Meat and egg & Cow's meat ${ }^{*}$, chicken ${ }^{\star}$, yolk, whole egg, liver, sausage, fish \\
\hline Cereal & Pasta $^{\star}$, homing ${ }^{\star}$, sweet biscuits ${ }^{\star}$, rice $^{\star}$, corn flour, crackers, cake, bread \\
\hline Tuber & $\begin{array}{l}\text { Potato }^{*}, \text { yam }^{*}, \text { carrot }^{*} \text {, biscuit flour } \\
\text { cheese bread }\end{array}$ \\
\hline Vegetable & $\begin{array}{l}\text { Pumpkin }{ }^{*}, \text { carrot }^{\star} \text {, beet }{ }^{*}, \text { chayote }^{*}, \text { zucchini, green beans, cauliflower, } \\
\text { tomato, eggplant, gherkin, cucumber, okra, jiló }\end{array}$ \\
\hline Fruit & $\begin{array}{l}\text { Apple }^{*} \text {, papaya }{ }^{*} \text {, banana }{ }^{*} \text {, orange } e^{*} \text {, pear, avocado, grape, strawberry, } \\
\text { mango, guava, kiwi, watermelon juice, acerola juice, cashew juice, guava } \\
\text { juice, passion fruit juice and pineapple juice. }\end{array}$ \\
\hline Artificial drink & Gelatin juice $^{\star}$, artificial juice ${ }^{\star}$, Gatorade \\
\hline Beans & Bean $^{*}$ \\
\hline Infusion & Coffee ${ }^{*}$, tea ${ }^{*}$ \\
\hline Leafy & Cabbage, spinach, broccoli, cabbage juice, lettuce, mustard, ora-pro-nobis \\
\hline Oil & Margarine \\
\hline Candies & Candy, lollipop, oreo, wafer, snacks, pizza, processed snacks \\
\hline
\end{tabular}

*: foods selected for the factor analysis.

among the variables [12]. The PCA for factor loadings above 0.40 was performed to assess the exploratory factorial structure of the 24-hour diet recall. The PCA was followed by a varimax orthogonal rotation. The database was built using Epi Info software version 6.04, and the statistical analysis was performed using Stata ${ }^{\circ}$ 9.0 Software.

The protocol of this study was approved by the Research Ethics Committee on Human Research of the Federal University of Jequitinhonha e Mucuri (FUVJM). The protocol number is $011 / 05(029 / 04)$.

\section{Results}

Of the 286 children initially selected for this study, 247, 226 and 211 of them were evaluated at the sixth, ninth and twelfth months of life, respectively. The losses were due to changes the household $(n=20)$, inability to locate the mother or address $(n=31)$, infant death $(n=1)$, refusal to participate $(n=4)$ and withdrawal throughout the follow-up period $(n=19)$.

There were no statistically significant differences in the demographic characteristics of the mothers and children who remained in the study compared to 
those who withdrew. This suggests that the losses at follow-up were random and therefore did not cause selection bias in the population (data not shown).

Table 2 displays the demographic and social characteristics of mothers and children in the cohort. About $40 \%$ of the children were females. The average age of the mothers was $24.7( \pm 6.8)$ years, and their mean schooling was $8.4( \pm 3)$ years of study. The frequency of breastfeeding in the sixth, ninth and twelve months was $77.3 \%, 66.3 \%$ and $54.5 \%$, respectively.

Sampling adequacy of factor analysis was assessed by KMO coefficient (coefficient $=0.655)$ and Bartlett's spherical test $(p<0.001)$, indicated that the correlations between the food items met the assumptions of the technique. When applied separately to the different ages, these results remained the same (Table 3).

Three dietary patterns were obtained after varimax rotation and denominated "Porridge", "Pap" and "Family Food" for the data in general and separately for the sixth, ninth and twelve months of life, as summarized in Table 3. The "Porridge" pattern explained $15.71 \%$ of the total variance in consumption, and it was composed of milk, sugar, and fortified flour. This pattern was negatively correlated with breast milk; thus consumption of breast milk decreased when the consumption of cow's milk increased. This pattern was also observed at six, nine and twelve months, illustrating the prevalence of this consumption pattern in all age groups.

The dietary pattern "Pap" was similar in all ages. This pattern, composed of tubers, vegetables and fruit, explained $14.5 \%$ of the total variance. When the analysis was repeated for each age separately, the sixth month differed with the inclusion of meat, and the ninth month differed with the inclusion of flours, although it was negatively charged.

The third pattern, "Family Food", explained $12.9 \%$ of the variance in consumption. It is composed of cereals, meat, vegetables and infusions. The pattern was similar at all ages, but with a small variation in the sixth month when it included the consumption of artificial drinks and excluded meat and infusions.

Table 2. Demographic and social characteristics of mothers and children in the cohort. Diamantina (MG), Brazil, $2004-2006$.

\begin{tabular}{ccc}
\hline Variáveis & N & $\%$ \\
\hline Mother age (years) & & 24.3 \\
$<19$ & 60 & 75.5 \\
$\geq 19$ & 187 & 50.2 \\
Mother schooling (years) & 124 & 49.8 \\
$\leq 8$ & 123 & 36.8 \\
$>8$ & & 63.2 \\
Marital status & 91 & \\
Without a partner & 156 & 40.5
\end{tabular}


Tabela 3. Factors loading distribution of food intake patterns after varimax rotation for children sample at $6,9,12$ months and general. Diamantina (MG), Brazil, 2004-2006.

\begin{tabular}{|c|c|c|c|c|c|c|c|c|c|c|c|c|}
\hline \multirow[t]{2}{*}{ Food } & \multicolumn{3}{|c|}{ General } & \multicolumn{3}{|c|}{6 months } & \multicolumn{3}{|c|}{9 months } & \multicolumn{3}{|c|}{12 months } \\
\hline & Porridge & Pap & $\begin{array}{l}\text { Family } \\
\text { food }\end{array}$ & Porridge & Pap & $\begin{array}{l}\text { Family } \\
\text { food }\end{array}$ & Porridge & Pap & $\begin{array}{l}\text { Family } \\
\text { food }\end{array}$ & Porridge & Pap & $\begin{array}{c}\text { Family } \\
\text { food }\end{array}$ \\
\hline Sugars & 0.74 & - & - & 0.82 & - & - & 0.69 & - & - & 0.52 & - & - \\
\hline Milks & 0.73 & - & - & 0.78 & - & - & 0.67 & - & - & 0.73 & - & - \\
\hline Human Milk & -0.70 & - & - & -0.67 & - & - & -0.75 & - & - & -0.69 & - & - \\
\hline Fortified flours & 0.53 & - & - & 0.50 & - & - & 0.52 & - & - & 0.68 & - & - \\
\hline Flours & - & - & - & 0.49 & - & - & - & -0.49 & - & - & - & - \\
\hline Tubers & - & 0.74 & - & - & 0.77 & - & - & 0.60 & - & - & 0.73 & - \\
\hline Vegetables & - & 0.71 & - & - & 0.76 & - & - & 0.55 & - & - & 0.70 & - \\
\hline Fruits & - & 0.65 & - & - & 0.65 & - & - & 0.65 & - & - & 0.66 & - \\
\hline Cereals & - & - & 0.80 & - & - & 0.65 & - & - & 0.74 & - & - & 0.74 \\
\hline Meats & - & - & 0.58 & - & 0.52 & - & - & - & 0.49 & - & - & 0.53 \\
\hline Leguminous & - & - & 0.57 & - & - & 0.73 & - & - & 0.46 & - & - & 0.57 \\
\hline Infusions & - & - & 0.48 & - & - & - & - & - & 0.45 & - & - & 0.54 \\
\hline Artificial drinks & - & - & - & - & - & 0.44 & - & - & - & - & - & - \\
\hline$\%$ variance explained & 15.71 & 14.51 & 12.94 & 16.98 & 16.50 & 10.62 & 14.91 & 13.35 & 12.02 & 15.24 & 13.73 & 12.73 \\
\hline $\begin{array}{l}\text { Total variance } \\
\text { explained (\%) }\end{array}$ & & 43.17 & & & 44.11 & & & 40.29 & & & 41.71 & \\
\hline
\end{tabular}

Factors extraction methods: principal component analysis.

\section{Discussion}

The dietary patterns and most important foods at each of the three ages described in this study confirm what other studies have found that is inadequate complementary feeding occurs, but now observed longitudinally, showing the persistence of the consumption pattern based on dairy products from six to twelve months of life. Three patterns identified in this study explain $43 \%$ of the total variability in children's diets. "Porridge" pattern was predominant in all ages studied.

The second major pattern in all ages studied, "Pap", was composed of tubers, vegetables and fruits in preparations such as puree or juice. There was little variation within the food groups resulting in a monotonous diet. The most frequently consumed foods have been potatoes, yams, white carrot, pumpkin, carrots, beets, chayote, banana, orange, apple and papaya.

At twelve months, "Family Food" would be expected to be the main dietary pattern because, by this age, the child should already be integrated into the family feeding pattern. However, this pattern explained less variation of the children's diets relative to the others patterns, not only at twelve months, but in all ages studied.

After six months, the child must continue to receive breast milk as the main 
food source accompanied by the gradual introduction of new foods, such as mashed vegetables, fruits, shredded and/or ground beef and cereals, and, eventually, the family's normal food [13]. However, this study identified the early consumption of other milk as a breast milk substitute and this breast milk substitute gain importance in dietary pattern during the second half of the first year of life. Despite the recommendations of organizations dedicated to the promotion of healthy feeding for the first two years of life, studies of different Brazilian regions [5] [8] [14] [15] [16] [17] and The National Survey on Demography and Health [18] have documented similar food intakes with different methodological approaches. The same dietary intake profile was observed in a Latin American study of children aged 0 to 23 months [19].

After the six months, complementary feeding should provide much of a child's nutritional requirements, especially of micronutrients such as iron and zinc. However, nutritional adequacy may be limited by the high frequency ingestion of cow's milk, as observed in this study. It is known that cow's milk has low iron bioavailability. In addition, can cause micro-intestinal hemorrhages, and contribute to the loss of iron through the stool, increasing the risk of anemia [20]. This risk is higher because of the low proportion of beans and meat in the diets of children at six, nine and 12 months [5] [8].

Infant formulas have a better bioavailability of iron compared to cow's milk, but they do not commonly substitute of breast milk (9.7\% at six months old, $3.5 \%$ at nine months old and $1.4 \%$ at 12 months) despite being the option of choice in these cases. The high cost of formula in Brazil may limit both its overall use and its duration of use [21]. It is still worth noting that dairy should not be the main source of iron at six months. Furthermore, the calcium content of dairy products interferes with mineral absorption.

The delayed introduction of animal food, i.e. meat may also contribute to the low supply of zinc, a mineral important for growth and immune system function [22]. Breast milk as a source of bioavailable zinc is not sufficient after six months of age, but the bioavailability of zinc in cow's milk is lower due to its close relationship to casein and competes with calcium for absorption [23], it is essential to include food sources of zinc, such as meat and yolk, in the child's diet.

Interestingly, eggs, especially the yolks, were not consumed at the minimum frequency set for inclusion in the factor analysis. Although this food is inexpensive and has a high nutritional value, it was infrequently chosen as an appropriate food during the first year of life.

The high consumption of cow's milk by children under two years old, not only in Minas Gerais, but also in areas of Northeast Brazil, [8] seems to reflect a cultural pattern of Brazilian mothers. The consumption of cow's milk may signal the limited influence of the health service and the limited adoption of health care and nutrition recommendations within the family unit. This may be due to an inappropriate health team approach to maternal beliefs and attitudes or to family resistance to changing health and nutritional habits. 
Although the Food Guide for six to 24 months [3] recommends that tubers, vegetables, fruits and meats must be present in the child's diet at six months of age, some of these foods are introduced later. Meat is not incorporated into the dietary pattern of these children at six, nine or 12 months. This dietary profile, with low a consumption of meat, has also been observed in other studies [5] [8].

Inadequate complementary food choices are also observed in the consumption of gelatin powder, prepared juice and juice powder in the "family food" pattern. It is important to emphasize that the consumption of these foods is contraindicated in children during the first year of life due to the presence of food additives, such as tartrazine, which is associated with allergic reactions [24]. Schumann et al. [25] also found the consumption of gelatin by breastfed infants in Rio de Janeiro, Brazil. The Acceptable Dietary Intake (ADI), defined by WHO experts, for tartrazine can not be applied to children less than twelve months old due to their immature liver function. However, as was observed in this study, other products containing additives were often consumed by children.

Different from our findings, Reidy et al., [26] in a study conducted in the USA in 2008 and published in 2017, found that most infants consumed appropriate types of milk (breast milk or iron-fortified infant formula) during the first 12 months and the minimum of whole cow's milk being consumed during this period.

The same complementary feeding profile was observed by Oliveira et al in a study carried out in Rio de Janeiro, Brazil, in 2006. The authors observed that only $60.2 \%$ of the children were being breastfed, but $99.7 \%$ received dairy products. Among infants, $46.4 \%$ also took other milk and $36.4 \%$ ate porridge. Although they are different methodologies, they point to the same scenario of complementary feeding of Brazilian children [27].

The dietary patterns observed in this study are incompatible with a consumption pattern that ensures adequate nutrition during the first year of life. The frequent replacement of breast milk by cow's milk during the second semester of life was observed. In addition, the "family food" pattern had lower explanatory power among the observed patterns of dietary consumption, even at twelve months of age, when it is expected that the child consumes the family food. These conditions contribute to an inadequate supply of nutrients during a critical period of development in which damage can be difficult to reverse.

It is worth highlighting the initiative of The Ministry of Health, which in 2012 proposed the "National Strategy for the Promotion of Breastfeeding and Healthy Complementary Feeding" [28]. The strategy aims to promote and support breastfeeding and healthy complementary feeding in the Health Care System. This innovative strategy intended to use the skills of health care professionals within the community and the mother's knowledge as a starting point for educational activities. However, this program has not been widely adopted. The lack of adoption raises doubts about the strategy's ability to reverse the current dietary patterns noted here and corroborated by other studies.

Finally, it must be recognized that, although feeding child takes place at the 
family level, customs and eating habits are also influenced by a broader context, which includes feeding culture, skills of health professionals, media, and, socioeconomic conditions.

\section{Conclusion}

In addition to the importance of short-term of complementary feeding for the maintenance of a healthy growth and development, the introduction of new foods directly influences the feeding habits of the child, indirectly affecting the nutritional status later in life. Thus, the promotion of healthy eating habits requires changes at various levels where the decisions about feeding are made, without losing sight of the scientific knowledge that is available.

\section{References}

[1] Dewey, K.G. and Adu-Afarwuah, S. (2008) Systematic Review of the Efficacy and Effectiveness of Complementary Feeding Interventions in Developing Countries. Maternal \& Child Nutrition, 4, 24-85. https://doi.org/10.1111/j.1740-8709.2007.00124.x

[2] World Health Organization (2001) Complementary Feeding: Report of the Global Consultation, and Summary of Guiding Principles for Complementary Feeding of the Breastfed Child. World Health Organization, 1-25.

[3] Brazil, Ministry of Health, Pan American Health Organization (2002) Food Guide for Brazilian children under two years of age. Series A. Standards and Technical Manuals; n. 107. Ministry of Health, Brasília.

[4] Victora, C.G., Smith, P.G., Vaugham, M.J.P., Nobre, L.C., Lombard, C., Teixeira, A.M.B., Fuchs, S.M.C., Morieira, L.B., Ggante, L.P. and Barros, F.C. (1987) Evidence for Protection by Breastfeeding against Infant Deaths from Infections Diseases in Brazil. Lancet, 2, 319-322. https://doi.org/10.1016/S0140-6736(87)90902-0

[5] Saldiva, S.R., Escuder, M.M., Mondini, L., Levy, R.B. and Venancio, S.I. (2007) Feeding Habits of Children Aged 6 to 12 Months and Associated Maternal Factors. Jornal de Pediatria (Rio ), 83, 53-58. https://doi.org/10.2223/JPED.1588

[6] Ferreira, J.V., Castro, L.M.C. and Menezes, M.F.G. (2009) Feeding in the First Year of Life: The Behavior of Health Professionals and the Practice of the Family. CERES, 4, 117-129.

[7] Mello, C.S., Barros, K.V. and Morais, M.B. (2016) Brazilian Infant and Preschool Children Feeding: Literature Review. Jornal de Pediatria (Rio ), 92, 451-463. https://doi.org/10.1016/j.jped.2016.02.013

[8] Assis, A.M.O., Gaudenzi, E.N., Gomes, G., Ribeiro, R.C., Szarfarc, S.C. and Souza, S.B. (2004) Hemoglobin Levels, Breastfeeding and Diet in the First Year of Life. Journal of Public Health, 38, 543-551. https://doi.org/10.1590/S0034-89102004000400010

[9] Neumann, A.I.C.P., Martins, I.S., Marcopito, L.F. and Araujo, E.A.C. (2007) Dietary Patterns Associated with Risk Factors for Cardiovascular Disease in a Brazilian City. Pan American Journal of Public Health, 22, 329-339. https://doi.org/10.1590/\$1020-49892007001000006

[10] World Health Organization (1998) Preparation and Use of Food-Based Dietary Guidelines. WHO Technical Report Series No. 880, WHO/FAO, Geneva. 
[11] Hair, J.F., Anderson, R.E., Tathan, R.L. and Black, W.C. (1998) Multivariate Data Analysis. 5th Edition, Prentice Hall.

[12] Moroco, J. (2003) Factor Analysis. In: Statistical Analysis Using SPSS, 2nd Edition, Edições Sílabo, Lisboa, 260-292.

[13] Pan American Health Organization and World Health Organization (2003) Guiding Principles for Complementary Feeding of the Breastfed Child. PAHO/WHO, Geneva.

[14] Galeazzi, M.A., Domene, S.M.A. and Schieri, R. (1997) Multicentric Study on Food Consumption. Rev of NEPA/UNICAMP (Discussion Notebooks) Special Issue.

[15] Corrêa, E.N., Corso, A.C.T., Moreira, E.A.M. and Kazapi, I.A.M. (2009) Complementary Feeding and Maternal Characteristics of Children Younger Than Two Years Old in Florianópolis, Santa Catarina, Brazil. Revista Paulista de Pediatria, 27, 258-264. https://doi.org/10.1590/S0103-05822009000300005

[16] Farias Júnior, G.D. and Osório, M.M. (2005) Alimentary Profile of Under-Five Year Old Children. Brazilian Journal of Nutrition, 18, 793-802. https://doi.org/10.1590/S1415-52732005000600010

[17] Oliveira, L.P.M.D., Assis, A.M.D.O., Pinheiro, S.M.C., Prado, M.d.S. and Barreto, M.L. (2005) Complementary Feeding in the First Two Years of Life. Brazilian Journal of Nutrition, 18, 459-469. https://doi.org/10.1590/S1415-52732005000400002

[18] Brasil, Ministério da Saúde (2008) Final Report of the National Demographic and Health Survey. National Survey of Demography and Health of Children and Women - PNDS 2006. Brasília. Ministry of Health.

[19] Roche, M.L., Creed-Kanashiro, H.M., Tuesta, I. and Kuhnlein, H.V. (2010) Infant and Young Child Feeding in the Peruvian Amazon: The Need to Promote Exclusive Breastfeeding and Nutrient-Dense Traditional Complementary Foods. Maternal \& Child Nutrition, 7, 284-294. https://doi.org/10.1111/j.1740-8709.2009.00234.x

[20] Ziegler, E.E. (2011) Consumption of Cow's Milk as a Cause of Iron Deficiency in Infants and Toddlers. Nutrition Reviews, 69, S37-S42. https://doi.org/10.1111/j.1753-4887.2011.00431.x

[21] Santos, C.S.d., Lima, L.S.d. and Javorski, M. (2007) Factors That Interfere in the Food Transition in Children Aged between Five and Eight Months: An Investigation of the Childcare System in Recife, Brazil. Brazilian Journal of Mother and Child Health, 7, 373-380. https://doi.org/10.1590/S1519-38292007000400004

[22] Mafra, D. and Cozzolino, S.M.F. (2004) The Importance of Zinc in Human Nutrition. Brazilian Journal of Nutrition, 17, 79-87. https://doi.org/10.1590/S1415-52732004000100009

[23] Wood, R.J. and Zheng, J.J. (1997) High Dietary Calcium Intakes Reduce Zinc Absorption and Balance in Humans. The American Journal of Clinical Nutrition, 65, 1803-1809.

[24] Rowe, K.S. and Rowe, K.J. (1994) Synthetic Food Coloring and Behavior: A Dose Response Effect in a Double-Blind, Placebo-Controlled, Repeated-Measures Study. The Journal of Pediatrics, 25, 691-698.

[25] Schumann, S.P.A., Polônio, M.L.T. and Gonçalves, É.C.B.d.A. (2008) Evaluation of Artificial Dye Intake by Children. Food Sci. Technol (Campinas), 28, 534-539. https://doi.org/10.1590/S0101-20612008000300005

[26] Reidy, K.C., Deming, D.M., Briefel, R.R., Fox, M.K., Saavedra, J.M. and Eldridge, A.L. (2017) Early Development of Dietary Patterns: Transitions in the Contribution of Food Groups to Total Energy-Feeding Infants and Toddlers Study, 2008. BMC 
Nutrition, 3, 5. https://doi.org/10.1186/s40795-016-0124-0

[27] Oliveira, M.I.C., Rigotti, R.R. and Boccolini, C.S. (2017) Factors Associated with Lack of Dietary Diversity in the Second Semester of Life. Cadernos Saúde Coletiva, 25, 65-72. https://doi.org/10.1590/1414-462x201700010204

[28] Brasil (2015) National Strategy for the Promotion of Breastfeeding and Healthy Supplementary Feeding in the Unified Health System: Implementation Manual/ Ministry of Health, Secretariat of Health Care - Brasília: Ministry of Health. 152 p. 